\title{
Infra Red Assisted Navigation for Automatic Lawn Mower Robot
}

\author{
Sivaguru J, Anush P
}

\begin{abstract}
The mobile robotics industries moving forward with innovative approach to solve the humanitarian problems. In this work, the scope is limited to cleaning backyard and front yard landscaping; the maintenance of these premises are mundane tasks which takes up lot of human effort and consumes time. Tasks like mow grass and dusting off the dead leaf's using gardening robot for lawns and play grounds could be given to robot for effective maintenance. In this work a cost-effective method of navigation and boundary defining of the lawn/play ground is attempted. A set of defined mowing operation is coded in the robot for path planning and boundary defining of the target. Robot docking station is done using same boundary wire technique for charging the battery and resuming the work as required. The lawn mower estimate distance moved using ground speed sensor.
\end{abstract}

Keywords-Automatic lawn mower, IR assisted navigation, path planning.

\section{INTRODUCTION}

Lawn Mower are vital source for keeping the garden well maintained [1][2]. Operating source for these machines could be just by pushing the mower forward required human labour [3] for this mundane work. The lawn mower related injuries is potentially useful to avoid further avoidances [4] accidents due to the rotation of blades to human user. Human resource could be utilized for more skill required tasks since the lawnmower are fitted with autonomous capabilities to navigate the lawn [5]-[7].

This paper presents autonomous guided path for given garden lawn. There have several development as prototype many manufactured various intelligent product development for autonomous lawn mowing [5], [7]-[14]. However, the cost of the development and deployment of those technologies is high and required increase setup time and user to add lot of infrastructure to the boundary setup and decreases the portability feature. Global position system (GPS) and inertial measurement unit (IMU) for autonomous vehicles [15] are widely used for navigation purpose, performance of these methods are accurate while outdoor without residential area occluded by walls, tree canopies interference while these create more challenges. Radio Frequency based demonstration for localization is shown by various authors [5][16], but they would require costly infrastructure. Vision based localization and IMU with ground speed sensor where they divided their task into learning and mowing phase [7]

Revised Version Manuscript Received on 10 September, 2019.

Sivaguru J, Department of Mechatronics Engineering, Kumaraguru College of Technology, Coimbatore, Tamil Nadu, India.

(Email: sivaguru.j.mce@kct.ac.in)

Anush P, Department of Mechatronics Engineering, Kumaraguru College of Technology, Coimbatore, Tamil Nadu, India.

(Email: anush.p.mce@kct.ac.in)

system employs landmarks based map estimator for acquire boundary wire and surrounding landmarks by observer to estimate the 3D position of landmarks, which is not flexibility portability are low, and required high computation power and time duration during training phase to actual deployment.

Our goal in this work is to provide a high-quality, daily lawn mowing service. Typical lawn size range in size from 30 x 49 square feet, and consist of unobstructed, immaculately maintained lawn. For matching quality of an experienced lawn mower human, the autonomous bot has needed a high-accuracy localization system. Benefit of this system is bot can operate before/after sunrise/sunset in complete darkness. This autonomous bot ideally should be operated on laws as large as 100 square meter, with monotonic scenery. This will reduce feature-based localization systems like laser-range finder with feature detection, vision-based localization; GPS is widely deployed in outdoor robots. Interestingly, these monotonic sceneries is also create high accuracy issues where human workers need to maintain desired parallel, straight passes might not be perfect where it may lead to a poor mowing pattern with banana-shaped or unparallel lines.

To overcome above limitations, we use prototype lawn mower with IR and ground unit speed senor to estimate and define the boundary of the lawn. For high-accuracy cost-effective solution four-wheel drive with wheel encoder is placed to determine the number of rotation each wheel has taken and do the correction as and when required to achieve the desired parallel paths. The installation, maintenance cost of bot is simple and affordable to the design.

The paper is organized as follows: In Section II, the methodology is described. Section III presents the design of the autonomous lawn mower. Section IV discusses results and Section $\mathrm{V}$ contains concluding remarks

\section{METHODOLOGY}

The intended design consists of behavior running concurrently to maintain the scenic beauty of the landscape. Lawn mower get the boundary information from the IR sensor placed on the bot. Bot should not wandering round at start or boundary, lawn mower must start moving parallel in its workspace, which is its basic behaviour.

To define the boundary Infrared sensors are used. For navigation purpose Ground speed sensors and Gyroscopic sensors are provided on the lawn mower. ' $C$ ' Programming guides for the communication between hardware. 


\section{A. IR Guided Boundary}

IR signal emitted by IRT1 and IRT2 is received by the bot by using infrared receivers provided in the bot. IRT1 defines the south boundary of the monotonic lawn. Similarly ITR2 defines the north boundary. Navigation using these sensors is described in the following section.

\section{B. Navigation of the lawn mower}

Parallel path and semicircular paths are controlled by controlling the driver motors of the all the four wheels. Boundaries are controlled by IR sensors provided in the lawn and bot.

\section{Hardware and Communication}

Field boundaries and the paths of the lawn mower are sensed by the various sensors and the information is communicated to the lawn mower. Communicating programs are coded in ' $\mathrm{C}$ ' language. This information controls the wheel rotation and hence the path of the lawn mower.

The overall layout of the lawn and the bots traversing strategy is shown in fig. 1 .

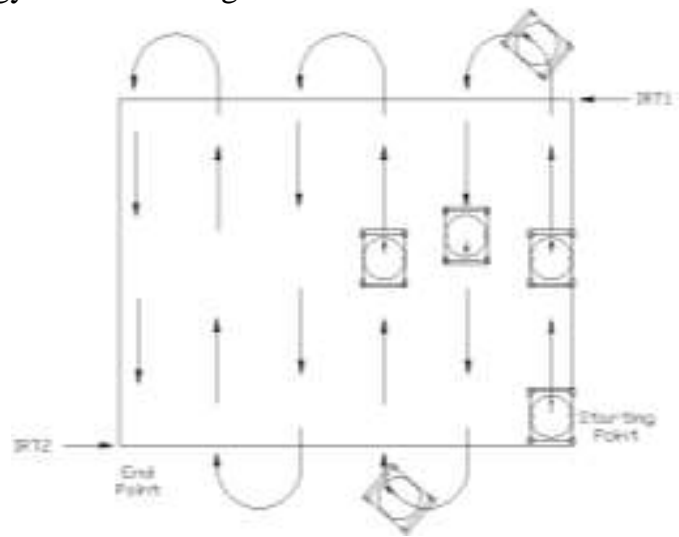

Fig.1. Lawn layout and Lawn traversing strategy

\section{DESIGN}

In this section, the structure of the lawn mower, sensor placement for navigation and Path planning are discussed. Typical drawing of the lawn mower is shown in the fig.2.

Forward direction of the lawn mower is indicated by the arrow mark.

\section{A. Lawn mower Structure}

Lawn mower has four wheels and a cutter blade. Cutter blade is attached in the bottom side of the second base plate (base plate 2) as shown in the fig. 2 .

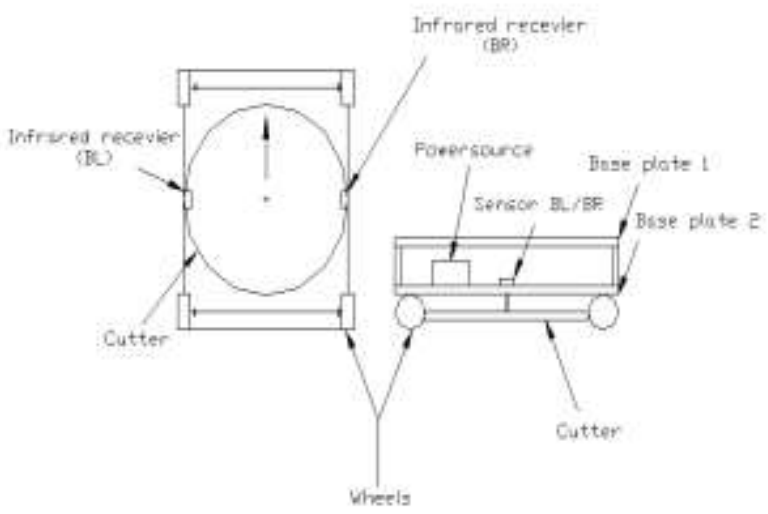

Fig 2. Lawn mower structure and sensors
Power souse is kept between the base plates. Four numbers of motors are attached to the four wheels to drive the mower. Wheels are fitted with the Ground speed sensor to measure the linear speed and for the accurate positioning of the lawn mower. Two numbers of Infrared receivers are attached with the lawn mower in the right and left side as shown in fig. 2 . Gyroscopic sensor is also built on the mower. It senses the angle of turn and drives the motors which are attached to the wheels accordingly so that the movement of the lawn mower is always in a straight parallel path.

\section{B. Sensor Plancement for Navigation}

Infrared Transmitters are placed on the monotonic lawn as show in the fig.2. Other sensors like Infrared receivers, Ground speed sensor and Gyroscopic sensor are placed in the lawn mower. Infrared receivers (BR and BL as indicated in the fig.2) are placed on the right and left side of the lawn mowers to receive the signals from the infrared transmitters ITR1 and ITR2. The size of the lawn is restricted by the capacity of the ITR1 and ITR2.

\section{Path Planning Process}

Lawn traversing strategy: Rectangular shape lawns can be covered by a combination of linear movements and semicircular curved paths. Number of linear motions and curved motions depends on the size of the lawn. Linear motions are obtained by the equal rotation of the four wheels. Semicircular motion is obtained by stopping the two inner wheels and rotating the two outer wheels.

For the linear and semicircular motion coding ' $C$ ' language is used. The flow chart for the same is as shown in the fig. 3 .

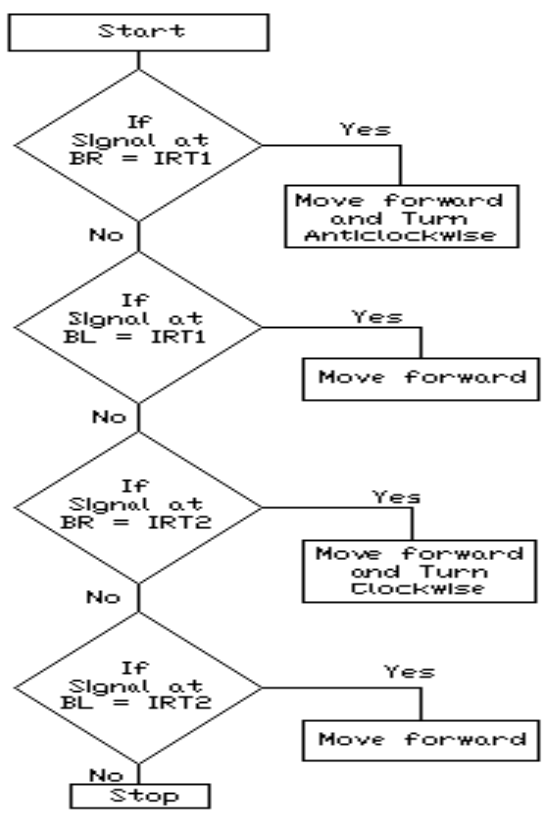

Fig.3. Flowchart for lawn mower

Here,

$\mathrm{BR}$ and $\mathrm{BL}$ - Infrared receiver placed at the right hand side and left hand side of the lawn mower respectively.

ITR1 and ITR 2 - Infrared transmitter located in the

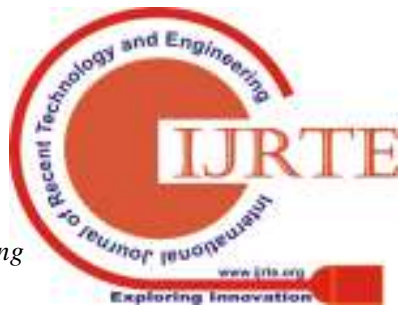


lawn whose locations are indicated in the fig. 2 in the previous section.

The conditions for the forward and semicircular motion are provided in the following table.

Table 1 Strategies for the lawn traversing

\begin{tabular}{|c|c|c|c|c|}
\hline $\begin{array}{c}\text { SI. } \\
\text { No }\end{array}$ & $\begin{array}{c}\text { Signal } \\
\text { from }\end{array}$ & $\begin{array}{c}\text { Bot } \\
\text { sensor at } \\
\text { Right } \\
\text { (BR) }\end{array}$ & $\begin{array}{c}\text { Bot } \\
\text { sensor at } \\
\text { Left } \\
\text { (BL) }\end{array}$ & $\begin{array}{c}\text { Action } \\
\text { Programmed }\end{array}$ \\
\hline 1 & $\begin{array}{c}\text { Field } \\
\text { sensor 1 } \\
\text { (IRT1) }\end{array}$ & TRUE & FALSE & $\begin{array}{c}\text { Move forward } \\
\text { and Turn } \\
\text { anti-clockwise }\end{array}$ \\
\hline 2 & $\begin{array}{c}\text { Field } \\
\text { sensor 1 } \\
\text { (IRT1) }\end{array}$ & FALSE & TRUE & Move forward \\
\hline 3 & $\begin{array}{c}\text { Field } \\
\text { sensor 2 } \\
\text { (IRT2) }\end{array}$ & TRUE & FALSE & $\begin{array}{c}\text { Move forward } \\
\text { and Turn } \\
\text { anti-clockwise }\end{array}$ \\
\hline 4 & $\begin{array}{c}\text { Field } \\
\text { sensor 2 } \\
\text { (IRT2) }\end{array}$ & FALSE & TRUE & Move forward \\
\hline
\end{tabular}

\section{RESULTS AND DISCUSION}

The designed lawn mower robot is depending on the wheel rotation. Wheel is the main component where the parallel path maintains and direction change for uninterrupted operation of the lawnmower. Feedback from the wheel rotation is collected from the ground speed sensor and if there is any change in the rotation of the parallel wheels the driving motor is directed to control the rotation of the wheels. Hence the straight parallel paths can be achieved using ground speed sensor.

Once the lawn mower reaches any one of the boundary it receives the signal from infrared transmitters. Depending upon the sensor input, that is, whether the signal is from IRT1 or IRT2 and the whether the receiver is BR or BL the bot decide the its movement. If BR gets signal from ITR1 it moves forward and takes anticlockwise turn. If the signal from ITR2 reaches to BR the bot moves forward and takes clockwise turn.

Similarly if BL gets signal from ITR1 or ITR2 the lawn mower moves in a straight parallel path.

\section{CONCLUSION AND FUTURE WORK}

This project provides a low cost solution for the rectangular shaped monotonous lawn in the range of 30 feet $x 49$ feet. However Irregular shapes of the front yards and back yards are to be dealt with the future work. Visual Odometer technique must be tested with the lawn robot for further enhancement of the operation. The lawn which is not monotones is also to be considered in the future work.

\section{REFERENCES}

1. J. Morris and J. Bagby, 'Measuring environmental value for natural lawn and garden care practices', Int. J. Life Cycle Assess., vol. 13, no. 3, pp. 226-234, 2008.

2. S. M. Gunn et al., 'Determining energy expenditure during some household and garden tasks', Med. Sci. Sports Exerc., vol. 34, no. 5, pp. 895-902, 2002.

3. Donald M. White, 'RIDING LAWN MOWER', 1991

4. D. G. Hottinger, I. Nasr, J. K. Canner, D. Kattail, R. Koka, and D. Schwengel, 'Incidence, distribution, and cost of lawn-mower injuries in the united states, 2006-2013', Public Health Rep., vol. 133, no. 5, pp. 570-577, 2018.

5. Vidhya, S., and B. Nagaraj. "Fuzzy based PI controller for basis weight process in paper industry." J Fuzzy Syst 4 no. 7 (2012): 268-272.

6. A. D. Smith, H. J. Chang, and E. J. Blanchard, 'An outdoor high-accuracy local positioning system for an autonomous robotic golf greens mower', Proc. - IEEE Int. Conf. Robot. Autom., pp. 2633-2639, 2012.

7. Chien Ouyang, 'ROBOTIC LAWN MOWER WITH NETWORK SENSORS', 2015.

8. J. Yang, S. J. Chung, S. Hutchinson, D. Johnson, and M. Kise, 'Vision-based localization and mapping for an autonomous mower', IEEE Int. Conf. Intell. Robot. Syst., pp. 3655-3662, 2013.

9. C. Roy, C. Deshmukh, V. Thawrani, and S. Dhabre, 'Automatic Lawn Mower using Renewable Energy Sources', IOSR, vol. 13, no. 5, pp. 60-62, 2018.

10. R. Andre Colens, 'ROBOTIC LAWNMOWER', 2013.

11. P. P. Dutta, A. Baruah, A. Konwar, and V. Kumar, 'A Technical Review of Lawn Mower Technology', vol. 4, no. 1, pp. 4-7, 2016.

12. Thomas H. Noonan, 'AUTONOMOUS LAWN MOWER', 1993.

13. K. K, P. Cheriyan, and A. K. J, 'Automatic Lawn Mower using Green Energy Sources', IJRITCC, vol. 5, no. 7, pp. 46-49, 2017.

14. rue du B. 5 André Colens and B.-1330 Rixensart (BE), 'SELF-PROPELLED LAWN MOWER', 2001.

15. R. Sivagurunathan, L. Sivagurunathan, and J. Chia Jun Hao, 'Design and Fabrication of Low Cost Portable Lawn Mower', Sch. J. Eng. Technol., vol. 5, no. 10, pp. 584-591, 2017.

16. S. Sukkarieh, E. M. Nebot, and H. F. Durrant-whyte, 'A high integrity IMU/GPS navigation loop for autonomous land vehicle applications - Robotics and Automation, IEEE Transactions on', vol. 15, no. 3, pp. 572-578, 2006

17. B. Ferris, D. Haehnel, and D. Fox, 'Gaussian Processes for Signal Strength-Based Location Estimation', Robot. Sci. Syst. II, 2006. 